\title{
Decision Support Systems for IT Service Management
}

\author{
Aileen Cater-Steel, University of Southern Queensland \\ Raul Valverde,Concordia University and CONAIC \\ Anup Shrestha, University of Southern Queensland \\ Mark Toleman, University of Southern Queensland
}

\begin{abstract}
Group-based Decision and Knowledge Support Systems have the potential to assist Information Technology Service Managers make sound decisions. We use narrative enquiry and reflective processes to review two recent projects that designed decision support tools for IT Service Management. The Software Mediated Process Assessment project includes a group decision support system to enable the selection of processes for assessment. The Decision Support Recommendation System for IT service operation used a knowledge base to provide recommendations specific to a problem domain such as IT service support. From the use of prior literature, rigorous methods and empirical evidence, contributions are made to Information Systems theory and ITSM practice. Outcomes from projects of this nature demonstrate exemplary cases of success stories where the primary research objective is to develop innovative solutions that work in practice and are grounded in academic rigour.
\end{abstract}

\section{Introduction}

An increasing number of organisations are turning to the IT service management (ITSM) model to adopt a more customer-focused and service-oriented approach in response to external factors such as regulation, competition, customer requirements, market pressures and economics. ITSM is a process-focused discipline for managing IT as services that deliver value to customers. The model, in essence, deemphasizes the management of technology and IT systems and instead focuses on the provision of a collection of end-to-end IT services to support the business of the organisation (Cater-Steel et al., 2013). Not unexpectedly, the increasing popularity of ITSM is accompanied by a proliferation of software tools to support processes.

Copyright (C) 200x Inderscience Enterprises Ltd. 
The aim of this paper is to highlight the growing importance of Group Decision Support Systems (GDSS) and Knowledge Based Systems (KMS) tools to improve ITSM decision making and processes. We review two recent industry-based projects that designed support tools for ITSM. Project A designs and develops a Software Mediated Process Assessment (SMPA) Tool for continual service improvement. Project B develops the architecture for a Decision Support Recommendation System (DSRS) for IT Service Operation.

This paper is structured as follows. To provide context and background, recent research on ITSM and the development of supportive software tools is reviewed. Then each of the selected research projects is described in detail. The discussion compares and contrasts the two projects in terms of scope, theories, methods and outcomes. Finally, the conclusion provides a summary, discusses contributions and limitations, and suggests future research directions.

\section{Background and Prior Work}

\section{IT Service Management}

To provide guidance for implementing the ITSM model, many organisations use the IT Infrastructure Library ${ }^{\circledR}$ (ITIL $®$ ) framework. Under the influence of the internationally active IT Service Management Forum (itSMF) the framework has gained worldwide acceptance among private as well as public sector organisations (Clacy and Jennings, 2007, Barafort et al., 2002, Galup et al., 2009, Hochstein et al., 2005b). Research carried out in Australia, Europe, US and South Africa has confirmed that organisations have benefited from adopting the framework (Hochstein et al., 2005a, Potgieter et al., 2005, Cater-Steel and McBride, 2007, Tan et al., 2009). The ITIL phenomenon led to the creation of the international standard for IT service management - ISO/IEC 20000 (ISO/IEC, 2011).

In the current ITIL version (2011 edition) the framework departs from its prior 'process silos' approach to take a lifecycle view of ITSM. Under this lifecycle view, ITSM processes are designed, created, transitioned into live environment and then operationally supported. This is reflected in the names of the five key books that describe the processes and functions structured over the stages of the service life cycle: Service Strategy, Service Design, Service Transition, Service Operation, and Continual Service Improvement. 
Decision Support Systems for IT Service Management

\section{Smart Tools to Support ITSM}

Incident management is one of the most widely adopted ITIL process, and often one of the first processes implemented by organisations (Marrone et al., 2014). Although ITIL-supported tools are available to provide basic functions to $\log$ and track incidents, it is not surprising that researchers have sought to develop more sophisticated tools to specifically support this process. For example, Cusick and Ma (2010) defined an approach to improve responses during an incident, aiming to improve and refine the treatment of the incident through the use of appropriate tools. The approach was tested in a division of an international firm. The researchers concluded that the approach was totally adherent to ITIL, proved to be very efficient, and realized the need to apply the approach to other methods and practices. Jäntti (2009) analysed the system requirements for incident management in accordance with ITIL processes. The requirements included requisition; status checking of the request; knowledge base, single contact point; and keeping records within the time limits defined in the SLA (Service Level Agreements). Tehrani and Mohamed (2011) considered a knowledge management approach was important for Service Desk tools and developed an ITIL-based tool to assist incident management. They applied the Case Based Reasoning technique in the ITIL-based tool. At Volkswagen in Germany Schmidt et al. (2014) developed a service-oriented framework for building reusable decision processes for ITSM.

Both projects presented in this paper create decision support systems. Recently, the potential contribution of decision support systems has become widely considered to enhance the decision making processes of managers and operational-level staff. The decision making process requires both knowledge and information. The knowledge management process involves gathering, analysing, storing, and sharing knowledge and information within the organisation (Phifer, 2011). Information provides clues to resolve an uncertainty and complexity of an issue, while the knowledge helps in understanding the ambiguity around the issues. A decision support system aids in decision making under the conditions of uncertainty and complexity (Zack, 2004). 


\section{Research method}

The methodology used to compile this research paper was based on narrative inquiry with reflective processes as an effective means to document the experiences of the leaders of the two research projects. The narrative inquiry approach entails the documentation and analysis of accounts of a specific domain of discourse, allowing the research participant to tell his or her own story (Hunter, 2004). Narrative inquiry has been used previously in Information Systems research, for example by Hunter and Tan (2001) to identify the major career path impacts of IS professionals, and by Cater-Steel et al. (2010) to compare different approaches to ITSM education.

As academics, we are encouraged to use reflective practice to prompt considered actions to enhance our teaching and research (Fry et al., 2009). This research was motivated by our desire to improve future ITSM research projects. After agreeing on the format of the narratives based on summaries of published research articles, each author individually prepared their account of the ITSM DSS project they led. We then reviewed the narratives and discussed and refined them to compare and contrast the approaches and outcomes. Each of the authors then had a subsequent opportunity to review and comment on the narratives. Through this process we were able to gain deeper understanding of the relative benefits and drawbacks to the approaches that were undertaken.

This paper reviews two recent projects that focus on the design of decision support tools for specific aspects of ITSM. For each project, the background for the project is provided, including a review of relevant literature. This is followed by a description of the research approach and methodology. The design, development, testing and evaluation of each tool is then described.

\section{Project A - Software Mediated Process Assessment (SMPA) Tool}

\section{Continual Service Improvement}

Continual Service Improvement (CSI) emphasizes the need for an ongoing effort to identify opportunities for improvement of weaknesses or failures within the lifecycle stages. ITIL guidance stresses that the "real work" begins after the development and roll-out of the new processes (OGC, 2011). This CSI requirement, which is consistent with the continual 
improvement principle in the ISO 9000 standards for quality management systems, is also ingrained in ISO/IEC 20000 to the extent that one of the clauses in the standard mandates that "there shall be a policy on continual improvement of the service management systems" (ISO/IEC, 2011).

The purpose of CSI is to continually align and re-align IT services to the changing external business conditions by identifying and making appropriate improvements to the ITSM processes (OGC, 2011). CSI is important to the business as it deals with the continuing relevance and responsiveness of the IT services to customers, while addressing the effectiveness and efficiency of the underlying ITSM processes.

CSI activities, however, are expensive as they are resource-consuming (OGC, 2011). Moreover, process improvement programs in general may be difficult to sustain and may even regress over time if they are not effectively managed (Harkness et al., 1996, Keating et al., 1999). To undertake CSI activities many organisations perform process assessments. These assessments involve the systematic measurement, analysis and reporting of the performance of core ITSM processes. The results are then used to evaluate the capabilities of these processes and drive process improvement activities.

\section{Selection of ITSM Processes for Assessment}

This case describes the first module in a Software Mediated Process Assessment (SMPA) tool. The tool has three modules as shown in Figure 1:

Module 1. Process selection module. Group decision support system (GDSS) to prioritise ITSM processes for improvement.

Module 2. Process capability assessment module. Online survey to collect process attribute scores.

Module 3. Assessment report. Calculates capability levels and compiles a report with specific recommendations. 


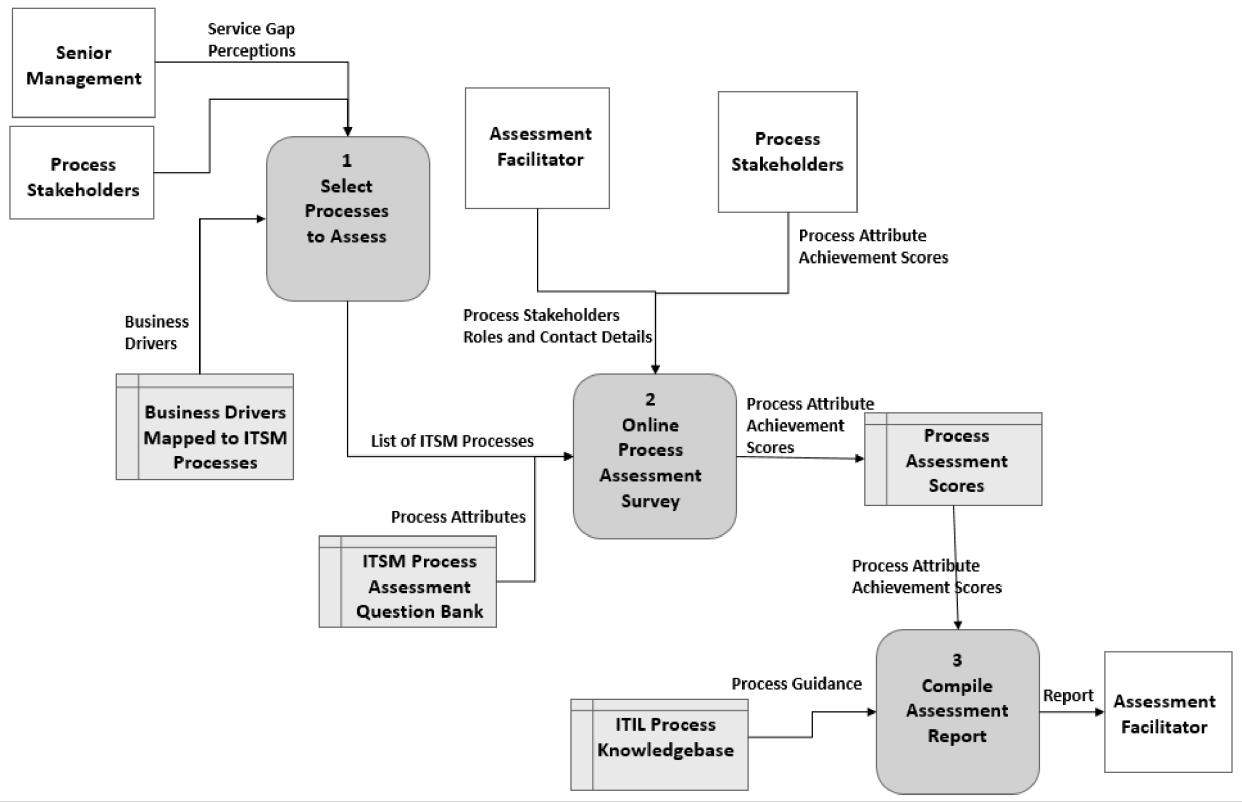

Figure 1. SMPA Tool - System Overview

The objective of Module 1 is to prioritise ITSM processes for assessment. Prior researchers have used DSS tools to select contractors (Enyinda et al., 2011), knowledge management tools (Grimaldi and Rippa, 2011), suppliers (Pitchipoo et al., 2012) and rapid prototyping processes (Zhang et al., 2014).

The research methodology is based on Design Science Research steps and Task-Technology theory as shown in Figure 2.

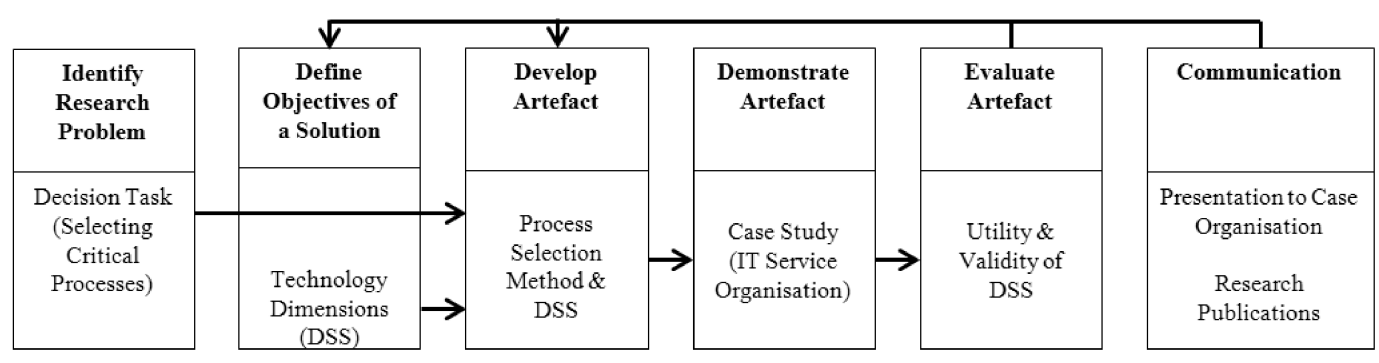

Figure 2. Research Methodology based on DSR steps and TTF theory (adapted from (Zigurs and Buckland, 1998) and (Peffers et al., 2008)) 
The SMPA uses a GDSS module to prioritise the ITSM processes for improvement in terms of two perspectives: business drivers and service gap perceptions. The Balanced Scorecard (BSC) (Kaplan and Norton, 1992a) is used to identify the business drivers and the service quality model (SERV-QUAL) (Parasuraman et al., 1985) is used to identify service gap perception factors. As shown in Figure 3 these models ensure that the ITSM processes are prioritised based on the key business drivers that have the highest impact on the business and are endorsed by key stakeholders. Inputs comprise the current ITSM processes in the organisation, service gap perception factors and current business drivers.

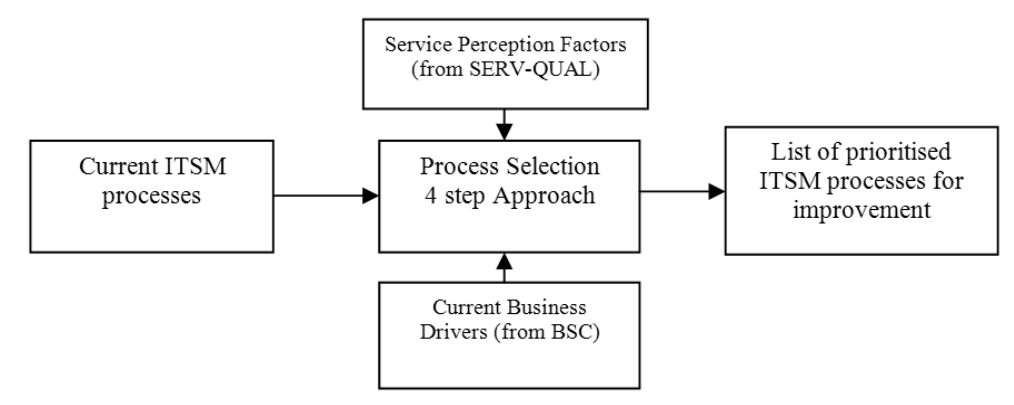

Figure 3. ITSM Process Selection Decision Model

The link between IT service processes and business objectives can be explained with the BSC as it presents a "balanced" analysis of organisations on a strategic level from four key perspectives: financial; customer; internal business; and innovation and learning (Kaplan and Norton, 1992b). Furthermore, the concept of BSC is well accepted in business as a core management tool (Rigby, 2011).

Even though the customer perspective of the BSC produces business drivers to align IT service processes to business goals, the approach ignores the perception of the key stakeholders of IT services. In order to query key stakeholders in regards to their perception of quality service, we incorporate a service gap perception survey.

The concept of service quality and its subsequent models originated from the marketing discipline. According to Grönroos (1990), there are three 
dimensions of service quality: technical quality refers to the outcome of the service; functional quality constitutes the process of the service provision; and the corporate image built upon the technical and functional qualities. Since our research is concerned with the IT service processes, we are concerned with the functional quality aspects that are proven to work well when measured using the SERV-QUAL model (Kang and James, 2004). The objective of using the SERV-QUAL model in our research is not for measuring service quality but for gap analysis to determine service gap perception factors that shape stakeholders' understanding of their role and preferences in executing IT service processes.

The GDSS tool facilitates online surveys for service gap perception (step 1); organises workshops to categorise processes (step 2); conducts online surveys for voting and pairwise comparison of business drivers (step 3); and calculates process scores to obtain the final prioritised ITSM process list for ITIL processes (step 4). The tool was developed in partnership with our industry research partner who provided the software platform. The online tool was developed using the Microsoft Azure ${ }^{\circledR}$ cloud platform (Microsoft, 2013) with features to automate online survey tracking and a facilitator console to manage the surveys and workshops. The tool also performs calculations of the process scores from the business drivers and service gap perception factors to generate the prioritised ITSM process list. Steps 1 and 2 provide service gap perception input while step 3 comprises business driver input. Step 4 then facilitates the output of the model. The workflow of ITSM process selection is illustrated in Figure 4. 
Decision Support Systems for IT Service Management

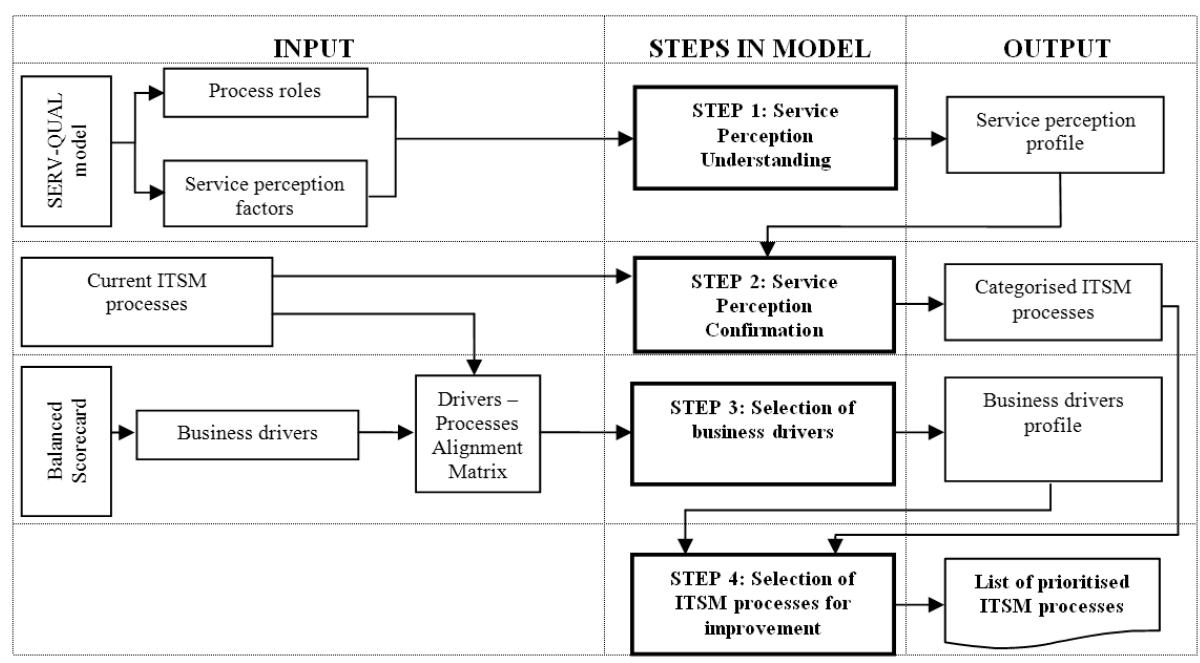

Figure 4. Workflow of ITSM Process Selection for Improvement

Step 1 Understand service gap perception. An online service gap perception survey is conducted across the stakeholders to determine what they perceive in regards to their understanding of IT service provision. Based on the SERV-QUAL model for gap analysis, we firstly identified three distinct stakeholder groups related to IT service provision: service beneficiary (customers); service provider management (process managers); and service provider workforce (process performers).

We analysed the five service gaps regarding service quality perception proposed by Parasuraman et al. (1985). Gap 1, 2 and 5 from the SERVQUAL model dealt with expectation-perception gap between and among customers and service providers. Gap 3 was the deviation of the actual service delivery from the expected service. Likewise, Gap 4 dealt with communication issues. We therefore grouped the five service gaps in three major themes: expectation-perception gap; expectation-delivery gap; and communication gap. To address these three service gaps, we identified the three most common factors in the ITSM model that underpin the service gap perception of stakeholders: value proposition; degree of confidence; and better communication. We then derive a total of nine specific service gap perception factors from the identified service gaps as listed in Table 1. Stakeholders complete the online survey with responses for each of the identified service gap perception factors. 
Cater-Steel, Valverde, Shrestha, Toleman

Table 1. Nine service gap perception factors mapped to three ITSM service gaps

\begin{tabular}{|c|c|c|c|}
\hline $\begin{array}{l}\text { Service gaps } \\
\text { (Problem Space) }\end{array}$ & $\begin{array}{l}\text { General } \\
\text { Perception factors } \\
\text { (Solution Space) } \\
\end{array}$ & Perspective & $\begin{array}{l}\text { Service gap perception } \\
\text { factors }\end{array}$ \\
\hline $\begin{array}{l}\text { Expectation - } \\
\text { Perception Gap }\end{array}$ & Value proposition & $\begin{array}{l}\text { Increasing } \\
\text { benefits } \\
\text { Decreasing } \\
\text { costs } \\
\text { Better } \\
\text { partnership }\end{array}$ & $\begin{array}{l}\text { Meeting expectations } \\
\text { Budget spend } \\
\text { effectiveness } \\
\text { Importance as a partner }\end{array}$ \\
\hline $\begin{array}{l}\text { Expectation - } \\
\text { Delivery Gap }\end{array}$ & $\begin{array}{l}\text { Degree of } \\
\text { confidence }\end{array}$ & $\begin{array}{l}\text { Customer } \\
\text { Staff } \\
\text { Supplier }\end{array}$ & $\begin{array}{l}\text { Customer focus } \\
\text { Staff morale } \\
\text { Supplier confidence }\end{array}$ \\
\hline $\begin{array}{l}\text { Communication } \\
\text { gap (external and } \\
\text { internal) }\end{array}$ & $\begin{array}{l}\text { Better } \\
\text { communication }\end{array}$ & $\begin{array}{l}\text { Channel } \\
\text { Understanding } \\
\text { Knowledge }\end{array}$ & $\begin{array}{l}\text { Communication channels } \\
\text { Business understanding } \\
\text { Process awareness }\end{array}$ \\
\hline
\end{tabular}

After conducting the service gap perception survey, the responses are used to produce a consolidated service gap perception profile. The service gap perception profile provides an understanding of current service provision as perceived by key stakeholders and allows contrasts between the different stakeholders' views to highlight misalignment between the provider (management and staff) and receiver of services. No consideration of ITSM processes is made in this step since it relates only to high-level service gap perceptions.

Step 2 Confirm service gap perception. After producing the service gap perception profile, the consistency of responses from different process roles is considered. A workshop is organised with the key stakeholders to confirm the service gap perception profile from step 1 and categorise the processes based on their perceived importance to the business.

In this step, the service gap perception survey results are reviewed with the workshop attendees to obtain a full consensus. Since the workshop attendees include service provider management (process managers) who would have completed the perception survey in step 1, this gives them an opportunity to revisit their understanding and compare and contrast with other stakeholder groups. This review is an important step for service managers to obtain an overall understanding of the service gap perception 
not only from their perspective but with insights from the customers and staff they manage. Finally, all workshop attendees are asked to allocate each of the current ITSM processes to one of five pre-defined categories in terms of their relative importance (critical, high importance, moderate importance, low importance and not important process categories) and a final consensus is reached on the categorisation of the processes.

Step 3 Selection of Business Drivers. Prior to developing the tool, we undertook research to create a list of ITSM-relevant business drivers for each BSC perspective as illustrated in Figure 5. Then in order to rank the processes that offer the greatest value in supporting each business driver we constructed a matrix to map each of the drivers to the ITSM processes. This mapping was performed by a panel of five ITSM experts who crossreferenced the purpose and goals of each process (derived from the ITIL framework and ITSM international standard ISO/IEC 20000) to each business driver. A three-point rating scale was used to signify the importance (low, medium and high) of the process in contributing to the business driver. In order to finalise the mapping of business drivers to ITSM processes, a Delphi technique in three rounds was conducted.

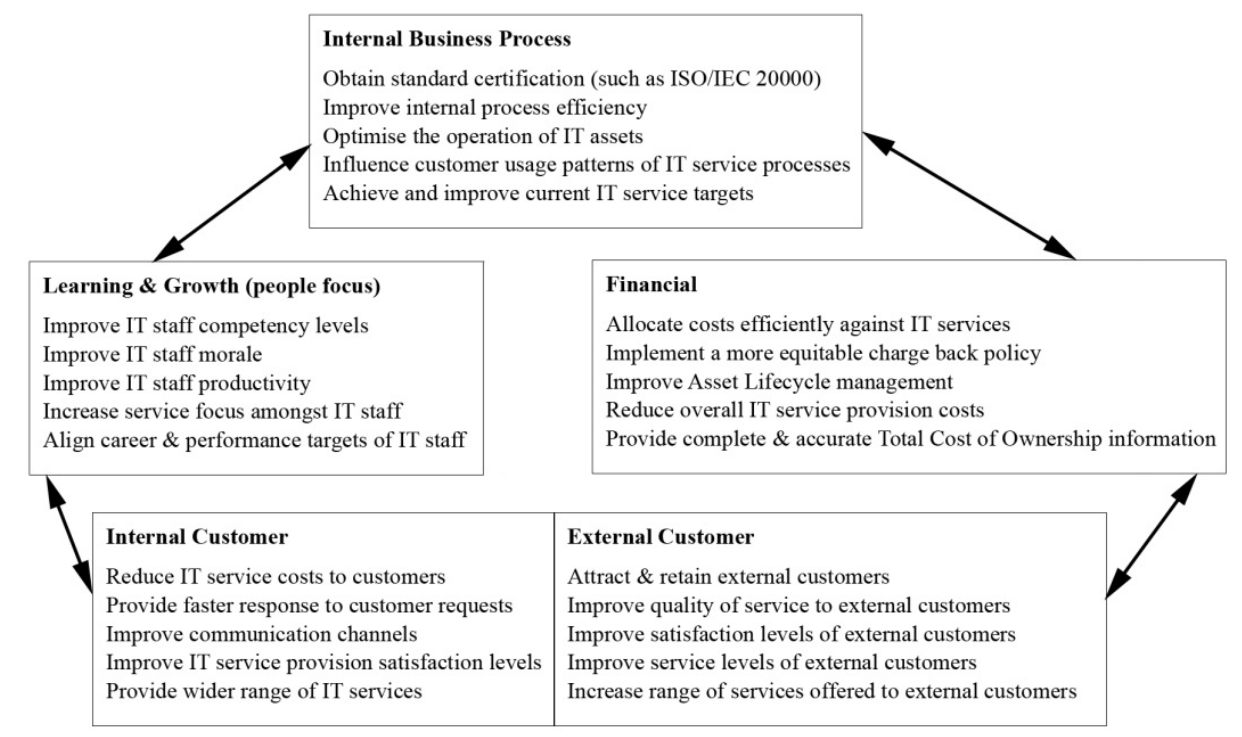

Figure 5. BSC perspectives of 25 business drivers 
Using the business driver-process mapping as input, the GDSS then conducts a driver ranking survey to shortlist the key business drivers. This survey comprises two exercises: a ranking technique to shortlist ten important business drivers from the initial list of 25 business drivers; and a pairwise comparison technique widely applied in the Analytic Hierarchy Process (Saaty, 2008) to compare the ten business drivers and produce a list of the top five business drivers.

Step 4 Selection of ITSM processes for improvement. For each of the current ITSM processes, a weighting and summing activity yields the overall process scores. The weights of the five business drivers are summed to calculate the process score. The maximum score possible for each process is 15 (i.e. score of 3 for all 5 drivers) and the minimum is 5 (i.e. 1 for each driver). Using this score and the score derived from the category of the process ( 1 to 5) from step 2, a final process rank is derived for each process and then the prioritised list of processes is produced. Processes are ranked from the input of both business drivers (provided by driver ranking) and service gap perception (provided by process category). Hence, the ranking of the processes in terms of their importance for improvement is justified from the key stakeholders' service gap perceptions of improvement and the process's impact on the business goals. Finally, this prioritised ITSM process list recommends to the service improvement managers the processes they should consider selecting for improvement.

Figure 6 provides a screenshot of the decision support tool. This screenshot illustrates that a total of 26 ITIL processes were considered and categorised based on the perception workshop using the GDSS tool. 


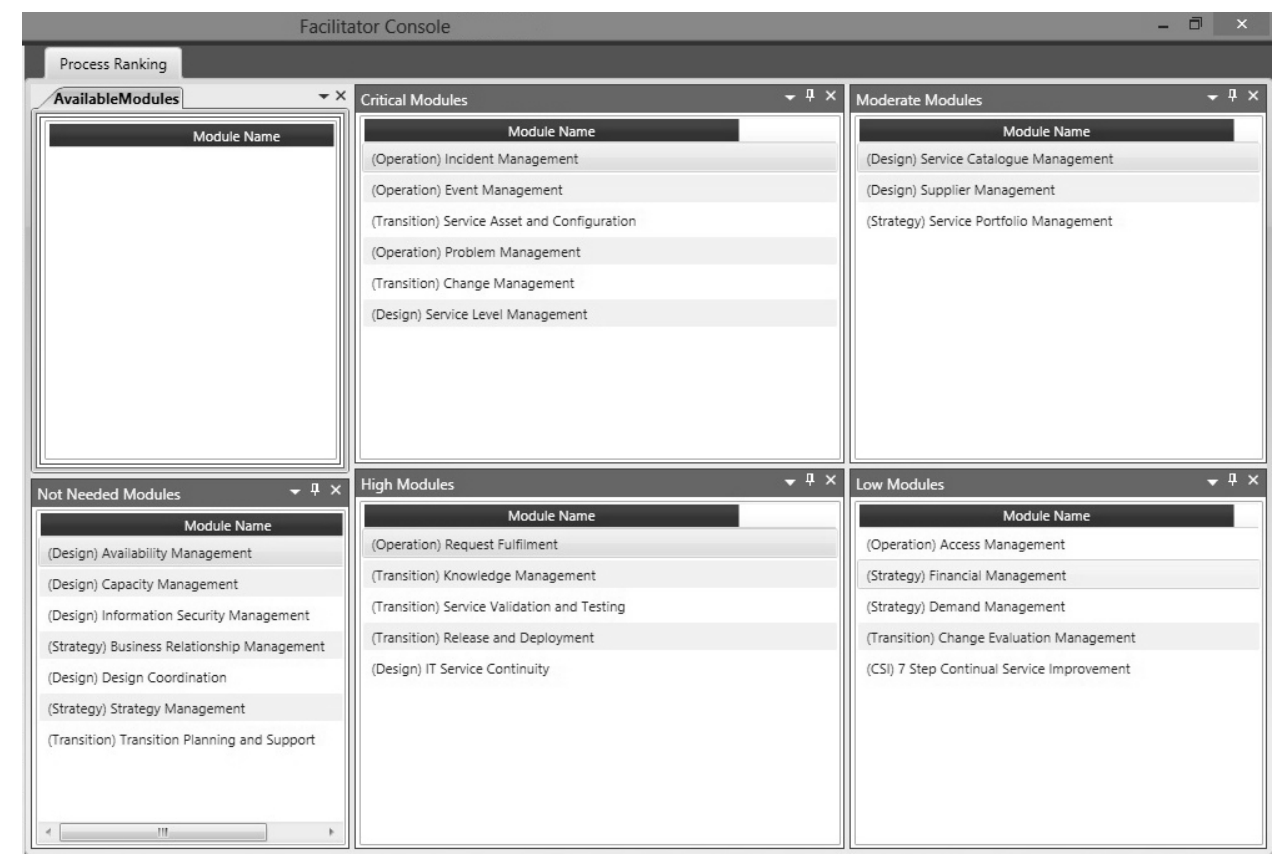

Figure 6. A screenshot of process ranking in the GDSS tool

\section{Demonstration of the Process Selection GDSS}

We implemented the tool at the IT Service Centre of Toowoomba Regional Council (TRC), a large local government authority in Australia. TRC employs about 50 IT staff who provide IT services to over 150,000 residents. The online service gap perception survey was followed by the perception workshop and then the driver ranking survey. After the prioritised ITSM process list was generated by the software tool, it was presented to the organisation. The IT service managers selected six critical processes to define a scope of their ITSM improvement project: incident management, event management, service asset and configuration management, problem management, change management and service level management.

\section{Evaluation of the Decision Support Tool}

We organised our evaluation based on the framework of Pries-Heje et al. (2008). The use of established frameworks such as the BSC and SERVQUAL models justifies the design of the artefact. This is an ex-ante 
artificial setting evaluation that took place continuously during the design process with several iterations of updates (Vaishnavi and Kuechler, 2004).

After the GDSS tool had been used, we obtained the ex post experience feedback from the workshop participants on the utility of the artefact and whether they agreed with the final prioritised ITSM process list suggested by the tool using a post-implementation interview.

The feedback from the service managers at the case organisation was extremely positive on the utility of the tool and on their perceptions of performance improvements regarding the process of selecting the most pertinent processes to improve. The case organisation initiated their ITSM improvement project by selecting the top six processes suggested by the artefact.

The actual performance improvements however can only be evaluated after observing the end results of the ITSM improvement projects. This requires longitudinal data and is beyond the scope of our present study. It is also obvious that the actual performance of the ITSM improvement projects is dependent on a number of external organisational factors such as top management commitment, budget and priorities for undertaking improvement activities, and effectiveness of the improvement plans.

Project B - Decision Support Recommendation System (DSRS) for IT Service Operation

\section{IT Service Operation}

ITIL provides a framework for IT service operations and infrastructure while CMMI (capability maturity model integration) provides a set of improvement goals and a point of reference for appraising current processes. Both CMMI and ITIL improve IT service processes as they could be used together to improve IT service quality and decrease the cost of service operations. IT supports process reengineering as an ongoing process, which requires a continuous monitoring of the key performance indicators (KPIs) at an operational and tactical level. A dashboard with targets signals as green light, yellow light, and red light can be established for each KPI. Recent advancements in telecommunications and computer networking technologies are able to integrate any distant and disparate systems together, making it possible to control a remote system from 
anywhere, based on decisions made in effective management of IT service support process (Talla and Valverde, 2013).

This case study provides a methodology on how to apply the ITIL framework to evaluate the alignment of the current IT service support processes with best practices and business processes, and subsequent integration into a decision support recommendation system (DSRS). The (DSRS) tool is proposed for effective management of all KPIs of IT service support processes and an on-going reengineering of IT service support processes for improved quality of support, at a reduced cost (Valverde et al., 2014).

\section{Case Study Research Method}

A case study methodology was chosen to emphasize and explore factors identified by the ITIL framework (Benbasat et al., 1987). The case study approach subsequently allowed us to identify directions for further investigation. The research in Benbasat et al. (1987) suggested the following three reasons that the case study approach is suitable for information systems: the researcher can study the information system in its natural setting; the researcher can answer "how" and "why" questions; and the case study approach is suitable for studies in which little formal research has been conducted previously.

A case study approach was used to identify a set of KPIs that were monitored by a decision support system (DSS) to trigger on-going reengineering of IT service support processes.

The case study organization selected was that of an IT services company located in Liverpool, UK. The selected company provides several types of support services to many organizations in the UK. For the research project, we selected a company that specializes in dental care. The case entails ten dental clinics in different locations of Liverpool. All these clinics are connected via a high-speed Wide Area Network (WAN). The data is centralized on the IBM RS6000 server located in the main dental center. Workstations are located in the user office and they are connected through the same network as well.

The project is explained by elaborating on the dental clinic organisational structure, main business services and client base. Since data gathering is an important part of case study research, we used questionnaires, review 
documents, archival records and observations to collect data for the project.

The information system research approach was used in this project, based on the method described by Burstein and Gregor (1999) and shown as Figure 7. They demonstrated the importance of recognizing the "System Development" approach and relevant criteria for guiding the validity and worth of such work.

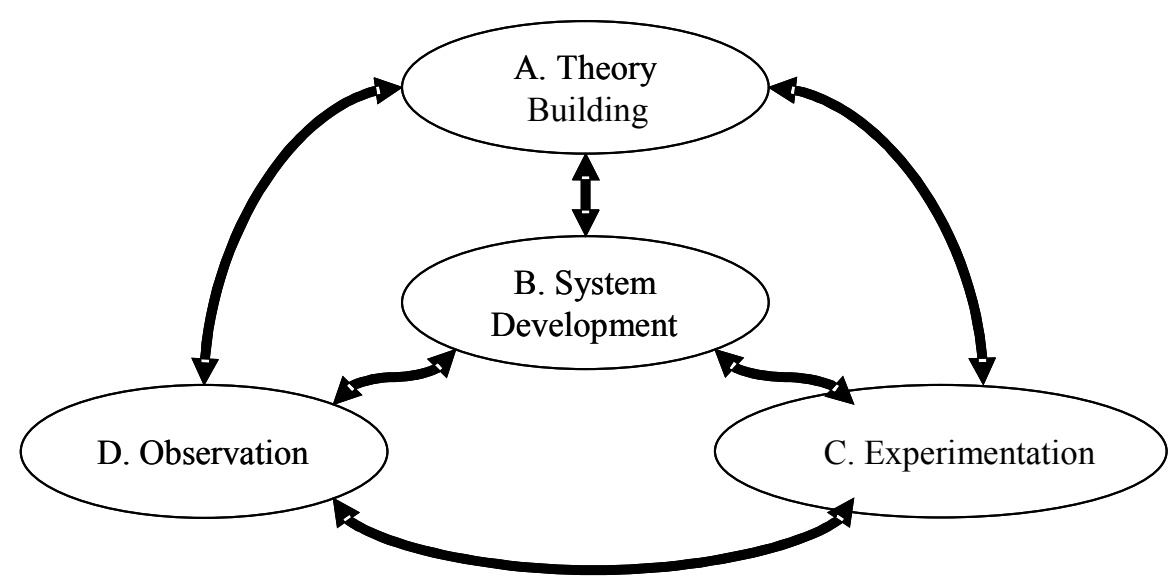

Figure 7. Information system research to phenomenon of interest

This form of research can be regarded as action research and is suitable for this project because "System Development" recognises other research fields next to system development, supports rapidly changing environments, and the use of the prototype as the natural approach.

The process is iterative, i.e., the cycle of action and reflection continually generates new insights. Area A in Figure 7 is the theory building phase, which is presented in the literature review, and area B is the development and design of a general system for the proposed DSS. Area C is about the implementation of the DSS prototype at a case study organisation. The prototype is based on theory building and the system development where underlying models are researched and applied in the system. Also information from the observation area D can be useful. For all areas, this is an iterative process where new findings can be added to the system. Area D is important to study the impact of changes in technology and 
systems in the organisation. These studies will generate new knowledge and improve acceptance of the system under construction. Area D can deliver useful information for the theory building, system development and the experimentation area.

The project comprised three stages. Firstly, archival records comprising the case study's problems logs were collected. These records are used to identify the areas of the IT services that will require modification for quality improvement.

In the second stage, a full analysis and benchmark of the ITIL framework in IT service operations was performed. A small portion of the ITIL framework was implemented and a group pretest-postest experiment was conducted. Twenty service management information support system users and IT representatives were selected via convenience sampling. A questionnaire was designed as a data-gathering device and administered before and after the implementation of the ITIL framework in the case study organisation. The test revealed that some improvement was achieved in eight processes: service desk, incident management, configuration management, change management, release management, capacity management, availability management, and security management.

The third stage of the project is the focus in this paper. In this stage, a DSS architecture was designed to provide recommendations specific to a problem domain, in this case IT service support.

\section{Tool design \& development}

The IT support process reengineering is an ongoing process that requires a continuous monitoring of the KPIs at the operational level and tactical level. The various targets such as green light, yellow light, and red light signals can be established for each KPI. Recent advancements in the telecommunications and computer networking technologies are able to connect any distant and disparate systems together, making it possible to control a remote system from any location, based on decisions made in effective management of IT service support process. A decision support system continuously monitors the KPIs and draws on a knowledge base to signal appropriate actions that can be performed on any remote system.

A decision support system (DSS) tool can be focused on providing recommendations specific to a problem domain such as IT service support. 
Therefore, a specialized DSS such as a recommendation system entails the manipulation of multiple attributes with a proper combination of data structure and scientific methodology vital to successfully achieve its goal. In effect, the recommendation system takes the form of a typical DSS with database, knowledge-base and inference components.

Figure 8 shows the architecture of the proposed DSS, implemented as a decision support recommendation system (DSRS) that has an interface with query processing capabilities and a dashboard; an inference engine for logic/algorithm computations; and the databases composed of the knowledge and operational data.

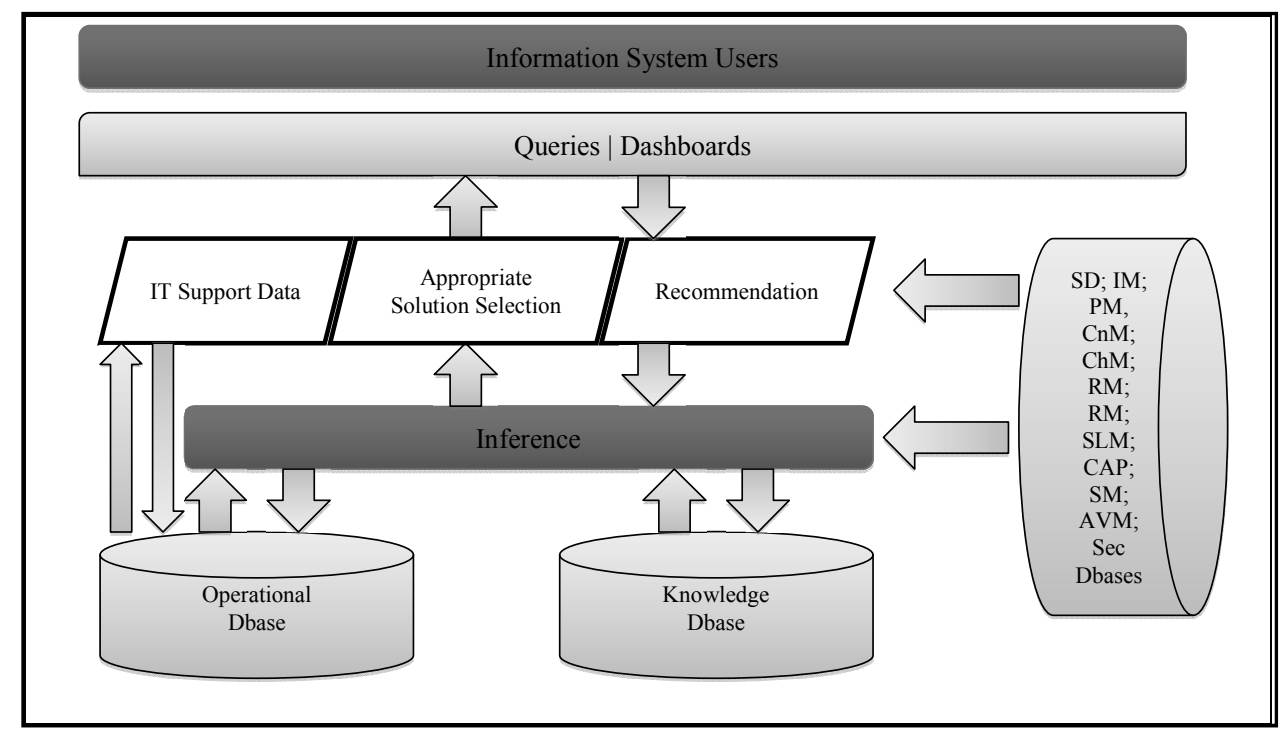

Figure 8. Architecture of a Decision Support Recommendation System

Any collaborative filtering system such as the one used at the query and dashboard layer must rely on a substantial database of users' past actions (questions, incident reports, conflict resolution outcomes, ratings, etc.) in order to find the similarities and differences between them and a given user. In our proposed architecture this would translate into a database of users' portfolios. Using methods from the recommendation system's body of knowledge, the process of using the DSRS would entail five primary steps: 
Step 1. Request service support and user assessment preferences. In order to generate initial recommendations, an assessment form of the current state of affairs needs to be included. This form would include some logic to provide a score.

Step 2. Selection of potential IT service support. Based on the score obtained, the system generates initial user support suggestions. This represents a filtering method, since in the beginning the users hold no portfolio of support requirements. The users are able to view available query and support threads, thereby further filtering them according to various preferences and usage criteria.

Step 3. Collaborative filtering methodology. Once the information of a number of support services has been logged, the collaborative filtering mechanism starts making recommendations.

Step 4. Inference generation based on criteria and preferences. In doing so, it starts to form the neighbourhood of $n$ similar user-problem sets with "similar" service support requests. Similarity can then be calculated based on the Jaccard Index. The procedure further examines the portfolios of the user-problem-solution sets in the same neighbourhood and counts the frequencies of the support services.

Step 5. Recommended IT service support. The service support userproblem with the highest frequency of occurrences is then presented to the service desk clerk/professional/user as a recommendation to the service support request.

The clerk/professional/user may choose among or make other selections from the ones not explicitly recommended to him/her. For example, a user with a problem with a printer calls a support clerk for help, the clerk requests information from the user about the problem and enters the given information in an assessment form. The recommendation system uses the form to recommend the IT service support with the highest frequency of occurrences to the support clerk (e.g. re-installation or upgrade of printer driver, change of printer cartridge, etc).

A note on the Jaccard index is worth providing at this point. The Jaccard index (rooted in macro-ecology) is defined as the study of ecological patterns and processes at scales of space and time, beyond the reach of manipulative experiments. This methodology relies on observational or inferential hypothesis tests, a fundamental pattern is the way in which the 
total number of species of interest increases as the sampled area increases (Leydesdorff, 2008). The increase in number of species is due to the fact that as more individuals are sampled, the chance of encountering additional species increase and that a larger area is likely to be more environmentally heterogeneous, thus containing additional species that differ in their niches.

The Jaccard index, also known as the Jaccard Similarity Coefficient (JSC), is a measurement that is used to identify the degree of similarity and diversity of two data sets. This major trend in 'similarity' research has been applied in various contexts such as in the field of numerical taxonomy, and wherever individuals characterized by a number of attributes are compared. The comparison is viewed as a means to identify the degree of resemblance or dissimilarity between a particular pair of individuals.

Use of proposed system: Based on the score obtained the system generates initial stock suggestions. The users are able to view available stocks (fifty in our case), sort or filter them according to various criteria. Once the information of a number of support services have been logged, the collaborative filtering mechanism starts making recommendations. In doing so, it starts to form the neighborhood of $n$ similarly user-problems sets with "similar" service support requests. The procedure further examines the portfolios of the user-problems sets in the same neighborhood and counts the frequencies of the support services. The service support user-problem with the highest frequencies of occurrences is then presented to the service desk clerk/professional/user as a recommendation to the request service support request.

The suggested criteria for the system development approach described by Burstein and Gregor (1999) will be used for evaluation of the system development work. A prototype of the proposed system will be constructed for this purpose in the next stage of the project.

\section{Challenges to date}

Although the results of all KPIs examined in this case study have demonstrated some improvement, it did not fully meet our initial expectations, as some of the processes did not have significant improvement. These processes include Problem Management, Service Level management and IT Service Continuity Management. The processes 
that observed some improvement were Service Desk, Incident Management, Configuration Management, Change Management, Release Management, Capacity Management, Availability Management and Security Management. There are two major possible explanations for this outcome pattern. Firstly, the duration of the testing phase is not long enough for the test group to experience ample improvement. For example, there were no major software maintenance upgrades performed during the test period. Secondly, some of the intended process reengineering efforts could not be fully implemented during the period of this case study, as it required more time, effort, and budget. For example, Problem Management required a focus group and a pool of technical expertise that was not available during the pilot project. However, a project such as this serves as a trigger for major reengineering of business processes. It could motivate the senior management to allocate appropriate budget, and plan a gradual implementation of process reengineering. The ITIL framework consists of a well evaluated set of best practice guidelines. It certainly serves as a tool for exploring process reengineering and improvements while meeting the budget constraints. The project required substantial coordination and consensus while identifying process improvements, establishing a process reengineering methodology, and constructing questionnaires for process evaluation.

\section{Discussion}

Although both projects addressed problems in the domain of IT service management, the scope of the projects varied significantly. This paper reports on the first module of the SMPA project that has the objective to objectively select ITSM processes to be assessed for continuous improvement.. The subsequent modules to perform the assessment and produce the assessment report have been completed for four processes: problem management, change management, configuration management and service level management. Further effort is underway by the industry partner to extend the SMPA prototype from four processes to the full range of service management system processes as defined in the international standard for ITSM (ISO/IEC 20000). In contrast, the DSRS project developed and used the architecture of the proposed decision support recommendation system that has an interface with query processing capabilities and a dashboard; the inference engine for logic/algorithm computations; and the databases composed of the 
knowledge and operational data. The next stage of this project requires the development of a prototype to implement the design and further engagement with the industry partner for the evaluation of the DSRS in terms of validity and utility.

The underlying theories and methods also varied between the two projects. In Project A, the novel combination of Balanced Scorecard and SERVQUAL models ensured the business priorities were incorporated with participants' perceptions of gaps in service provision to prioritise ITSM processes in need of improvement. Project A followed the Design Science Research approach. The "System Development" approach promoted by Burstein and Gregor (1999) was followed in project B. This DSRS project used an inference-based DSS architecture that provides a powerful querying interface with a dashboard to its users in order to extract recommendation items for decision support from the operational databases. Regardless of different problem domains and research methods, two distinct similarities exist, namely:

1. The parent discipline of IT Service Management and processoriented solution architecture;

2. A knowledge base of ITIL-based recommendations in the solution architecture.

\section{Conclusion}

Research and practical contributions have been claimed from both projects. Project A's design has made a unique contribution in the integration of BSC, SERVQUAL, and ITIL models to develop the GDSS as a research artefact. For practitioners the project demonstrated a useful and cost effective process to select ITSM processes for assessment and continual service improvement.

The Project B DSRS contribution is twofold: practical and theoretical. From a practical perspective, a methodology was proposed on how to apply the ITIL framework for the reengineering of IT service support processes. This methodology is demonstrated using a case study with empirical data for its measurement and analysis and used the results to propose theoretically a decision support system (DSS) for IT service support providing better means of monitoring the need for reengineering. The DSS architecture is presented and elaborated. 
Both projects show that academic researchers can make valuable contributions to the design and investigation of innovative software tools. However, effective transition of these tools to industrial use requires their integration into, and evaluation within, the industrial and business context. In some cases the innovation required is not so much the design of a new tool but its adaptation to the pattern of use within the organisation.

Software tools play a vital role in helping organisations achieve productivity and in assuring the quality and integrity of their products and processes. Productivity is enhanced by tools that automate processes or minimise the cognitive and physical effort required of those undertaking a task. Integrity is enhanced by tools that apply procedures without fear or favour, for example in the selection of ITSM processes as shown in the SMPA project A.

The models and systems developed form a base for subsequent research, implementation and evaluation that will contribute to efforts such as the International Standards for ITSM and process assessment and inferencebased DSS architectures.

\section{Acknowledgements}

Removed for peer review.

ITIL $®$ and IT Infrastructure Library ${ }^{\circledR}$ are the registered trademarks of AXELOS Ltd.

\section{Reference List}

BARAFORT, B., DI RENZO, B. \& MERLAN, O. Benefits Resulting from the Combined Use of ISO/IEC 15504 with the Information Technology Infrastructure Library (ITIL). In: OIVO, M. \& KOMISIRVIÖ, S., eds. 4th International Conference on Product Focussed Software Development and Process Improvement (PROFES), 2002. LNCS 2559, Springer-Verlag, 314-325.

BENBASAT, I., GOLDSTEIN, D. K. \& MEAD, M. 1987. The Case Research Strategy in Studies of Information Systems. MIS Quarterly, 11, 369-387.

BURSTEIN, F. \& GREGOR, S. The systems development or engineering approach to research in information systems: an action research perspective. In: HOPE, B. \& YOONG, Y., eds. 10th Australasian 
Conference on Information Systems, 1999 Wellington, NZ. Victoria University of Wellington.

CATER-STEEL, A., HINE, M. J. \& GRANT, G. 2010. Embedding IT Service Management in the Academic Curriculum: A Crossnational Comparison. Journal of Global Information Technology Management, 13, 64-92.

CATER-STEEL, A. \& MCBRIDE, N. 2007. IT Service Management Improvement - an Actor Network Perspective. European Conference on Information Systems. St Gallen, Switzerland.

CATER-STEEL, A., TAN, W.-G., TOLEMAN, M., ROUT, T. \& SHRESTHA, A. 2013. Software-Mediated Process Assessment in IT Service Management. 13th International conference, SPICE 2013. Bremen: Springer.

CLACY, B. \& JENNINGS, B. 2007. Service Management: Driving the Future of IT. Computer, 40, 98-100.

CUSICK, J. \& MA, G. 2010. Creating an ITIL inspired incident management approach: roots, response, and results. Network Operations and Management Symposium Workshops. IEEE/IFIP.

ENYINDA, C. I., OGBUEHI, A. O. \& UDO, G. 2011. A Decision Support Model for Contractor Selection in a Government Procurement Supply Chain: Evidence from an Emerging Market. Journal of Management Policy \& Practice, 12, 9-17.

FRY, H., KETTERIDGE, S. \& MARSHALL, S. 2009. A Handbook for Teaching \& Learning in Higher Education: enhancing academic practice, New York, NY, Routledge.

GALUP, S., DATTERO, R., QUAN, J. \& CONGER, S. 2009. An Overview of IT Service Management. Communications of the $A C M$, 52, 124-127.

GRIMALDI, M. \& RIPPA, P. 2011. An AHP-based framework for selecting knowledge management tools to sustain innovation process. Knowledge \& Process Management, 18, 45-55.

GRÖNROOS, C. 1990. Service Management and Marketing, Lexington, MA, Lexington Books.

HARKNESS, W. L., KETTINGER, W. J. \& SEGARS, A. H. 1996. Sustaining Process Improvement and Innovation in the Information Services Function: Lessons Learned at the Bose Corporation. MIS Quarterly, 20, 349-368. 
Decision Support Systems for IT Service Management

HOCHSTEIN, A., TAMM, G. \& BRENNER, W. 2005a. Service-Oriented IT Management: Benefit, Cost and Success Factors. In:

BARTMANN, D., RAJOLA, F., KALLINIKOS, J., AVISON, D., WINTER, R., EIN-DOR, P., BECKER, J., BODENDORF, F. \& WEINHARDT, C. (eds.) 15th European Conference on Information Systems. Regensburg, Germany.

HOCHSTEIN, A., ZARNEKOW, R. \& BRENNER, W. 2005b. ITIL as common practice reference model for IT service management: formal assessment and implications for practice. IEEE International Conference on e-Technology, e-Commerce and eService. Hong Kong.

HUNTER, M. G. 2004. Qualitative Research in Information Systems: An Exploration of Methods. In: WHITMAN, M. E. \& WOSZCZYNSKI, A. B. (eds.) The handbook of information systems research. Idea Group inc.

HUNTER, M. G. \& TAN, F. Information Systems Professionals in New Zealand: Reflective Career Biographies. International conference of the Information Resources Management Association, May 20222001 Toronto, Canada. 132-133.

ISO/IEC. 2011. ISO/IEC 20000:2011 Information technology - Service management - Part 1: Specification.

JÃNTTI, M. 2009. Defining requirements for an incident management system: a case study. International Conference on Systems. IEEE.

KANG, G.-D. \& JAMES, J. 2004. Service Quality Dimensions: An Examination of Grönroos's Service Quality Model. Managing Service Quality, 14, 266-277.

KAPLAN, R. S. \& NORTON, D. P. 1992a. The Balanced ScorecardMeasures That Drive Performance. Harvard Business Review, 70, 71-9.

KAPLAN, R. S. \& NORTON, D. P. 1992b. The Balanced ScorecardMeasures that Drive Performance. Harvard Business Review, 70, 71-79.

KEATING, E., OLIVA, R., REPENNING, N., ROCKART, S. \& STERMAN, J. 1999. Overcoming the Improvement Paradox. European Management Journal 17, 120-134.

LEYDESDORFF 2008.. On the normalization and visualization of author co-citation data: Salton's Cosine versus the Jaccard index. Journal 
of the American Society for Information Science and Technology, 59(1), 77-85

MARRONE, M., GACENGA, F., CATER-STEEL, A. \& KOLBE, L. M. 2014. IT Service Management: A Cross-national Study of ITIL Adoption. Communications of the Association of Information Systems (CAIS), 39, 865-892.

MICROSOFT. 2013. Windows Azure Features Overview [Online].

Microsoft. Available: http://www.windowsazure.com/enus/home/features/overview [Accessed 10 February 2013].

OGC 2011. ITIL Continual Service Improvement, London, TSO for the Office of Government Commerce.

PARASURAMAN, A., ZEITHAML, V. A. \& BERRY, L. L. 1985. A Conceptual Model of Service Quality and its Implications for Future Research. Journal of Marketing, 49, 41-50.

PEFFERS, K., TUUNANEN, T., ROTHENBERGER, M. \& CHATTERJEE, S. 2008. A design science research methodology for information systems research. Journal of Management Information Systems, 24, 45-77.

PHIFER, B. 2011. Next-Generation Process Integration : CMMI and ITIL Do Devops. Cutter IT Journal, 24, 28-33.

PITCHIPOO, P., VENKUMAR, P. \& RAJAKARUNAKARAN, S. 2012. A distinct decision model for the evaluation and selection of a supplier for a chemical processing industry. International Journal of Production Research, 50, 4635-4648.

POTGIETER, B. C., BOTHA, J. H. \& LEW, C. Evidence that use of the ITIL framework is effective. 18th Annual Conference of the National Advisory Committee on Computing Qualifications, 10-13 July 2005 Tauranga, NZ.

PRIES-HEJE, J., BASKERVILLE, R. \& VENABLE, J. R. Strategies for Design Science Research Evaluation. 16th European Conference on Information Systems, 2008 Galway, Ireland.

RIGBY, D. K. 2011. Management Tools 2011: An Executive's Guide. MA, USA: Bain \& Company, Inc.

SAATY, T. L. 2008. Relative Measurement and its Generalization in Decision Making. The Analytical Hierarchy/Network Process. RACSAM, 102, 251-318.

SCHMIDT, K., VON DER DOVENMÜHLE, T. R. H. \& GÓMEZ, J. M. 2014. Service-oriented framework for building reusable decision 
processes - in the domain of ITSM. Intelligent Decision Technologies, 8, 69-79.

TALLA, M. \& VALVERDE, R. 2013. An Implementation of ITIL Guidelines for IT Support Process in a Service Organization. Internatonal Journal of Information and Electronics Engineering, 3, 334-340.

TAN, W., CATER-STEEL, A. \& TOLEMAN, M. 2009. Implementing IT service management: a case study focussing on critical success factors. Journal of Computer Information Systems (JCIS), 50, 1-12.

TEHRANI, A. R. F. \& MOHAMED, F. Z. M. 2011. A CBR-based Approach to ITIL-based Service Desk. Journal of Emerging Trends in Computing and Information Sciences, 2.

VAISHNAVI, V. \& KUECHLER, W. 2004. Design Science Research in Information Systems [Online]. Available: http://www.desrist.org/design-research-in-information-systems [Accessed 10 February 2013].

VALVERDE, R., SAADE, R. \& TALLA, M. 2014. ITIL-based IT service support process engineering. Intelligent Decision Technologies, 8, 111-130.

ZACK, M. 2004. The Role of DSS technology in Knowledge Management. IFIP TC8/WG8.3 International Conference.

ZHANG, Y., XU, Y. \& BERNARD, A. 2014. A new decision support method for the selection of RP process: knowledge value measuring. International Journal of Computer Integrated Manufacturing, 27, 747-758.

ZIGURS, I. \& BUCKLAND, B. K. 1998. A Theory of Task/Technology Fit and Group Support Systems Effectiveness. MIS Quarterly, 22, 313-334. 